International Journal of

Environmental Research and

Public Health

ISSN 1660-4601

www.mdpi.com/journal/ijerph

Article

\title{
HIV Risky Sexual Behaviors and HIV Infection Among Immigrants: A Cross-Sectional Study in Lisbon, Portugal
}

\author{
Sónia Dias $^{1{ }^{1} *}$, Adilson Marques ${ }^{2}$, Ana Gama ${ }^{1}$ and Maria O. Martins ${ }^{1}$ \\ 1 Instituto de Higiene e Medicina Tropical - Centro de Malária e Outras Doenças Tropicais, \\ Universidade Nova de Lisboa, Rua da Junqueira ${ }^{\circ}$ 100, Lisboa 1349-008, Portugal; \\ E-Mails: anafgama@gmail.com (A.G.);mrfom@ihmt.unl.pt (M.O.M.) \\ 2 Faculdade de Motricidade Humana, Universidade de Lisboa, Estrada da Costa, \\ Cruz Quebrada-Dafundo 1499-002, Portugal; E-Mail: amarques@fmh.ulisboa.pt \\ * Author to whom correspondence should be addressed; E-Mail: smfdias@yahoo.com; \\ sfdias@ihmt.unl.pt; Tel.:+351-213-652-600; Fax:+351-213-632-105.
}

Received: 1 July 2014; in revised form: 23 July 2014 / Accepted: 12 August 2014 /

Published: 20 August 2014

\begin{abstract}
This study aimed to examine risky sexual behavior, its associated factors and HIV infection among immigrants. A participatory cross-sectional survey was conducted with 1187 immigrants at the National Immigrant Support Centre, in Lisbon (52.2\% female; $34.0 \%$ Africans, 33.8\% Brazilians, 32.2\% Eastern Europeans). About 38\% of participants reported $\geq 2$ sexual partners in the previous year, $16.2 \%$ both regular and occasional sexual partners (last 12 months), 33.1\% inconsistent condom use with occasional partners, and $64 \%$ no condom use in the last sexual intercourse. Unprotected sex in the last sexual intercourse was more likely among women, Africans, those older, with elementary education, those married and those who didn't receive free condoms in the previous year. No condom use was less likely among those having only occasional sexual partners and both regular and occasional sexual partners. One third of participants had never been tested for HIV. Those never tested reported more frequently inconsistent condom use than those ever tested. Overall, $2.0 \%$ reported being HIV positive (2.5\% of men; $4.4 \%$ of Africans); $4.3 \%$ admitted having a STI in previous year. HIV-positive immigrants reported high-risk sexual behaviors. Tailored interventions to promote awareness of HIV serostatus among immigrants as well as culturally adapted risk reduction strategies should be strengthened.
\end{abstract}


Keywords: immigrants; HIV infection; risky sexual behavior

\section{Introduction}

The HIV epidemic continues to be a major public health concern in the European Union $[1,2]$. Increased international migration, particularly from highly endemic countries, has been acknowledged as one of the major factors influencing the epidemiology of HIV in Europe and contributing to the changing pattern of HIV transmission in this region, where in the recent years sexually transmitted cases have been on the rise [3]. Estimates indicate that approximately $40 \%$ of the HIV diagnosed cases during 2007-2011 in Europe were in migrants [1].

Migration had been recognized to be associated with increased high risk sexual behaviors [4,5]. Previous research indicate that a considerable amount of immigrants report to have multiple partners and to not use condom consistently with both occasional (casual partner with no committed relationship) and regular (main, stable partner) partners [6-9], which renders this population particularly at risk for HIV infection. Explanations of the increased vulnerability of immigrants to HIV infection include the long periods away from family and partners, the associated need to seek companionship to compensate for the alienating aspects of the migration experience and the fewer social controls on behavior [9,10], but also the experience of social exclusion and lack of legal protection that often translate in lesser means of protection and poorer health status [7,9], and barriers to health services (related to their legal status, socioeconomic conditions, language and cultural difference) [3,11-13].

Despite the evidence of disproportionate HIV risk among migrants and increasing numbers of immigrants in the European context, there are few studies aimed to examine the extent of HIV infection, risky sexual behavior and its determinants among these populations. Additionally, many immigrants have not even been systematically included in HIV surveillance systems, as undocumented and recent immigrants who are omitted in the population census and records. Also, many groups underuse health services where surveillance data is reported (mainly due to mistrust or lack of knowledge about services available and migrants' health rights). Furthermore, in many cases data are not collected in a way that allows disaggregated analysis (in many countries no data is collected on variables as country of birth or ethnic group) [14,15].

Knowledge on HIV infection and risk behavior among immigrants is greatly needed to inform HIV prevention and control national programs as well as to provide valuable evidence for appropriate interventions in this population. This is particularly relevant in Portugal as it is one of the countries presenting the largest burden of infection in Western Europe-data estimates that in 2011 it had one of the highest incidence rates ( 11.8 per 100,000 population; 17.2 per 100,000 males and 6.7 per 100,000 females) and the second highest HIV prevalence (0.7\% among adults aged 15-49 years old) in the European Region [16,17]. Also, in the last decades Portugal has received many immigrants (the foreign-born population represent $8.3 \%$ of the total population in Portugal), mainly from countries with high HIV prevalence as most Portuguese-speaking African countries, Eastern European countries and Brazil [17-19]. In 2012, 29.4\% (228) of the newly diagnosed cases in Portugal referred to immigrants: 
66.4\% from Sub-Saharan Africa, 20.0\% from Latin America, 11.4\% from Europe [20]. This study aimed to examine risky sexual behaviors, its associated factors and HIV infection among immigrants in the Lisbon Metropolitan Area.

\section{Methods}

\subsection{Study Design and Population}

A cross-sectional survey was conducted with immigrants in the Lisbon Metropolitan Area. This area has currently the highest concentration of immigrant population in the country. Official data indicate that, in 2011, 44\% of the immigrant population in Portugal resided in the Lisbon region (around 188,259 and an undetermined number of undocumented persons excluded in the official statistics) [21]. A participatory approach was used: representatives of governmental organizations (public health services), non-governmental organizations (NGOs) and associations of African, Brazilian and Eastern European immigrants (who work in outreach projects in the areas of health promotion, HIV prevention and social support with immigrant communities) actively collaborated in all phases of the study.

\subsection{Sampling and Data Collection}

The study sample included 1187 immigrants who were interviewed at the National Immigrant Support Centre (NISC) in Lisbon over a 1 month period (February) in 2011. The NISC is part of the High Commission for Immigration and Intercultural Dialogue. Within a friendly environment, it provides integrated answers to needs faced by immigrants residing in Portugal (e.g., regularization process, interaction with public services) regardless of legal status or any other criterion. It brings together in one place different public institutions in the areas of health, education, social security, employment and justice [22,23].

All immigrants who visited the NISC premises during working hours were approached and invited to participate. The inclusion criteria were being an immigrant, defined as a non-national person who migrated to Portugal for the purpose of settlement [24], and being $\geq 18$ years old. The proportion of refusals was $9.7 \%(n=127 ; 57.7 \%$ were female $)$. No further information was collected from those who refused.

Data were collected through an anonymous structured questionnaire. Given the sensitive nature of the subject under investigation, the interviews took place in a quiet and isolated room at NISC offices to ensure privacy and comfort of participants. The questionnaire was applied by trained interviewers from immigrant communities, recruited and selected in collaboration with NGOs and immigrant associations. Interviews were applied in Portuguese - it is the official language of Africans and Brazilians in Portugal and many Eastern Europeans are fluent in Portuguese. In the few cases of Eastern Europeans who weren't fluent in Portuguese, specific interviewers applied the questionnaire in the native language. The questionnaire was administered using pen and paper. The interviewers training included information about the questionnaire, the data collection procedures and general interview techniques. 
Anonymous participation and confidentiality of data was guaranteed. Informed consent was obtained. The study was approved by the Ethical Committee of Instituto de Higiene e Medicina Tropical, Universidade Nova de Lisboa.

\subsection{Instrument}

The questionnaire comprised items on sociodemographic characteristics, sexual behaviors, HIV testing, self-reported HIV infection and other STI, use of health services and prevention initiatives. In more detail:

Sociodemographic characteristics: These included sex, age (continuous variable), educational level ("elementary", "secondary", "higher"), marital status ("single", "married", "divorced or separated" and "widowed"; for analysis these options were dichotomized into "unmarried"- single/divorced or separated/widowed — and "married"), professional situation ("employed part-time", "employed full-time", "working-student", "student", "unemployed" and "retired"; for analysis these options were dichotomized into "non-employed" - student/unemployed/retired-and "employed"-employed part-time/employed full-time/working-student), perceived monthly income ("very insufficient", "insufficient", "sufficient" and "more than sufficient"; for analysis these options were dichotomized into "insufficient" and "sufficient"), and migration-related characteristics such as origin (response options included a list of countries which were then aggregated into "African", "Brazilian" and "Eastern European"), length of stay (in months for those residing in Portugal for $<1$ year, and in years for those residing for $\geq 1$ year) and immigration status ("undocumented", "documented").

Sexual behaviors: Participants were asked about age at first sexual intercourse (in years); engagement in sexual intercourse (yes/no), number and type of sexual partners, commercial sex (yes/no), sex with a same-sex partner (yes/no) and condom use by type of sexual partner in the reference period of 12 months; type of sexual partner and condom use in the last sexual intercourse. Regarding type of sexual partner, two response options were used (regular/occasional partner) regular sexual partner was defined as a person with whom one has sexual intercourse and has plans for further long term or committed relationship; occasional sexual partner was defined as a person with whom one has sexual intercourse (without payment) and has no plans for further long term or committed relationship [8]. As these response options were not mutually exclusive, for the analysis they were categorized into "only regular", "only occasional" and "regular and occasional". Engagement in commercial sex was defined as having had sexual intercourse with a person involving money or goods exchange between the two parties [25]. Regarding condom use in the last 12 months, participants were asked how often a condom was used (by him/herself or his/her sexual partner) during their sexual relations, having three possible response options (always/sometimes/rarely or never). For analysis this variable was dichotomized into consistent (always) and inconsistent (sometimes/rarely or never) condom use. Participants were also asked whether a condom was used (by him/herself or his/her sexual partner) in their last sexual intercourse, being the possible response options "yes" and "no".

HIV testing: Participants provided information on whether they had been tested for HIV ever and in the previous 12 months, both questions with "yes"/“no" response options. 
HIV/STI status: Participants were asked to self-report their current serostatus for HIV and their serostatus for other sexually transmitted infections (STIs) in the last 12 months.

Use of health services and prevention initiatives: Participants were asked about ever use of health services in Portugal, ever attendance of a sexual and reproductive health consultation and having received free condoms in the previous 12 months, all with "yes"/"no" response options.

The questionnaire was designed in order to provide data for the second generation indicators created in accordance with international guidelines [26,27]. The items used in the questionnaire were also based on other international HIV research projects on migrants [28-30]. The instrument was constructed along with feedback provided by the partners of the study. The questionnaire was pre-tested with members of immigrant communities; few amendments were made to improve clarity and appropriateness of the questions to the study populations.

\subsection{Data Analysis}

Data analysis was performed using IBM SPSS Statistics v.22. The bivariate associations between sociodemographic characteristics, migration-related variables, sexual behaviors, HIV testing, self-reported infection, use of health services, prevention initiatives and gender were assessed using $\chi^{2}$ and Fisher's exact tests when appropriate. Logistic regression analyses were performed to estimate the crude odds ratios (OR), adjusted OR and 95\% confidence intervals (CI) of factors associated with no condom use in the last sexual intercourse. For analysis of sexual behaviors in the previous 12 months, 176 participants were excluded as they haven't reported sexual intercourse during this period.

\section{Results}

\subsection{Characteristics of Participants}

The socio-demographic and migration-related characteristics of the male and female participants are shown in Table 1. In brief, 52.2\% of the sample was female. Approximately two thirds of the participants were 25-44 years old. Overall, 34\% were Africans (from Portuguese-speaking African countries: Angola, Cape Verde, Guinea Bissau, Mozambique, and Sao Tome and Principe), 33.8\% were Brazilians and 32.2\% Eastern Europeans (from Ukraine, Moldavia, Russia, Romania, Belarus and Bulgaria). About 38\% had secondary education, more men than women $(p=0.028)$. More than a half of participants were not married. A third reported being undocumented, $47.1 \%$ were non-employed and $57.6 \%$ perceived their monthly income as insufficient. Mean length of stay in Portugal was 7.5 years $( \pm 7.5)$.

Table 1. Socio-demographic and migration-related characteristics by gender.

\begin{tabular}{|c|c|c|c|c|c|c|c|}
\hline & \multicolumn{2}{|c|}{ Total } & \multicolumn{2}{|c|}{ Men } & \multicolumn{2}{|c|}{ Women } & \multirow[t]{2}{*}{$p^{a}$} \\
\hline & $\mathbf{n}$ & $\%$ & $\mathbf{n}$ & $\%$ & $\mathbf{n}$ & $\%$ & \\
\hline Total & 1187 & 100 & 567 & 47.8 & 620 & 52.2 & \\
\hline Age (years) $(n=1187)$ & & & & & & & 0.173 \\
\hline $18-24$ & 189 & 15.9 & 101 & 17.8 & 88 & 14.2 & \\
\hline $25-44$ & 751 & 63.3 & 356 & 62.8 & 395 & 63.7 & \\
\hline $45-65$ & 247 & 20.8 & 110 & 19.4 & 137 & 22.1 & \\
\hline
\end{tabular}


Table 1. Cont.

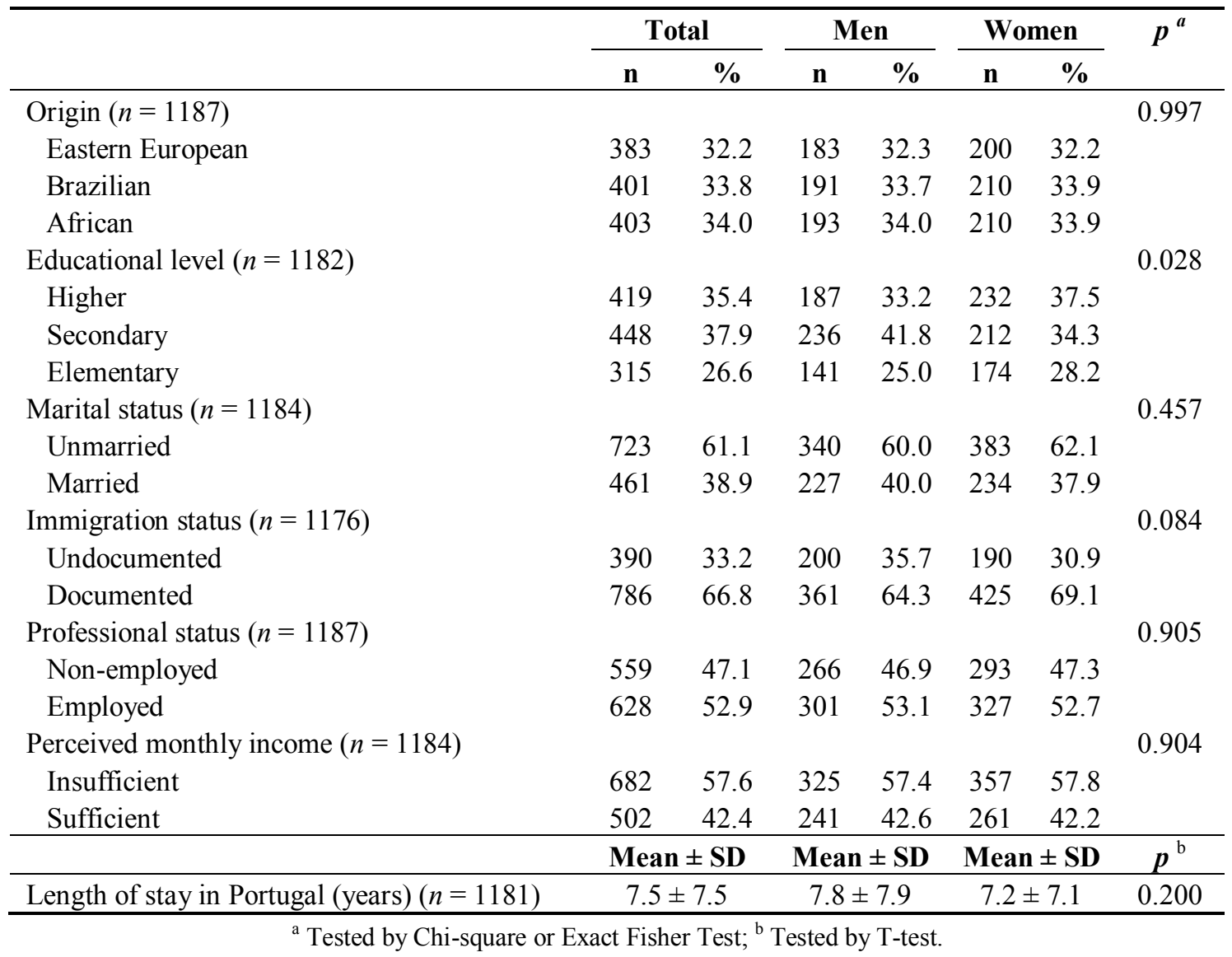

\subsection{Risk Sexual Behaviors, HIV Testing and HIV Infection}

Table 2 presents the data on risk sexual behaviors, HIV testing and reported HIV infection of the participants stratified by gender. Compared to women, men reported lower mean age at first sexual intercourse and higher number of sexual partners in the last year. Also, a higher proportion of men reported having both regular and occasional sexual partners in the last year and having their most recent sexual intercourse with an occasional partner. Also, a higher proportion of men reported engagement in sexual intercourse with same-sex partners and in commercial sex in the previous year, comparing to women.

Condom use with occasional partners in the last 12 months was inconsistent among $33.1 \%$ of participants, significantly more women than men $(44.8 \%$ and $28.7 \%$, respectively). Inconsistent condom use with regular partners was reported by $81.7 \%$ of participants, with no significant differences across gender. About $73 \%$ of women and $54.2 \%$ of men didn't use condom at their most recent sexual intercourse.

Approximately $38 \%$ of participants reported having never been tested for HIV, more men than women; of those ever tested, $63.4 \%$ were not tested in the last year. Those never tested reported more frequently inconsistent condom use with occasional partners $(42.7 \%$ compared to $28.9 \%$ of those ever tested for HIV,$p=0.034)$ and with regular partners $(85.2 \% v s .79 .8 \%$ of those ever tested for HIV, $p=0.05$ ). 
Table 2. Risk sexual behaviors, HIV testing, reported HIV infection, use of health services and prevention initiatives by gender.

\begin{tabular}{|c|c|c|c|c|c|c|c|}
\hline & & tal & & en & & men & \\
\hline & Mea & \pm SD & Mea & \pm SD & Mea & \pm SD & $p^{\mathrm{a}}$ \\
\hline Age at first sexual intercourse $(n=975)$ & 16.9 & \pm 2.9 & 16. & \pm 2.9 & 17.5 & \pm 2.8 & $<0.001$ \\
\hline & $\mathbf{n}$ & $\%$ & $\mathbf{n}$ & $\%$ & $\mathbf{n}$ & $\%$ & $p^{\mathbf{b}}$ \\
\hline $\begin{array}{l}\text { Number of sexual partners in the previous } \\
12 \text { months }(n=974)\end{array}$ & & & & & & & $<0.001$ \\
\hline 1 partner & 604 & 62.0 & 233 & 50.0 & 371 & 73.0 & \\
\hline 2-3 partners & 256 & 26.3 & 147 & 31.5 & 109 & 21.5 & \\
\hline$\geq 4$ partners & 114 & 11.7 & 86 & 18.5 & 28 & 5.5 & \\
\hline $\begin{array}{l}\text { Type of sexual partners in the previous } \\
12 \text { months }(n=998)\end{array}$ & & & & & & & $<0.001$ \\
\hline Only regular & 737 & 73.8 & 284 & 59.9 & 453 & 86.5 & \\
\hline Only occasional & 99 & 9.9 & 77 & 16.2 & 22 & 4.2 & \\
\hline Regular and occasional & 162 & 16.2 & 113 & 23.8 & 49 & 9.4 & \\
\hline $\begin{array}{l}\text { Sexual intercourse with same-sex partners in } \\
\text { the previous } 12 \text { months }(n=1002)\end{array}$ & & & & & & & 0.007 \\
\hline No & 943 & 94.1 & 437 & 92.0 & 506 & 96.0 & \\
\hline Yes & 59 & 5.9 & 38 & 8.0 & 21 & 4.0 & \\
\hline Commercial sex in the previous 12 months $(n=1011)$ & & & & & & & 0.002 \\
\hline No & 972 & 96.1 & 450 & 94.1 & 522 & 97.9 & \\
\hline Yes & 39 & 3.9 & 28 & 5.9 & 11 & 2.1 & \\
\hline $\begin{array}{l}\text { Type of sexual partner at the most recent sexual } \\
\text { intercourse }(n=1008)\end{array}$ & & & & & & & $<0.001$ \\
\hline Regular & 827 & 82.0 & 348 & 73.0 & 479 & 90.2 & \\
\hline Occasional & 181 & 18.0 & 129 & 27.0 & 52 & 9.8 & \\
\hline $\begin{array}{l}\text { Condom use with regular partners in the } \\
\text { previous } 12 \text { months }(n=890)\end{array}$ & & & & & & & 0.068 \\
\hline Consistent & 163 & 18.3 & 83 & 21.0 & 80 & 16.2 & \\
\hline Inconsistent & 727 & 81.7 & 313 & 79.0 & 414 & 83.8 & \\
\hline $\begin{array}{l}\text { Condom use with occasional partners in the previous } \\
12 \text { months }(n=248)\end{array}$ & & & & & & & 0.017 \\
\hline Consistent & 166 & 66.9 & 129 & 71.3 & 37 & 55.2 & \\
\hline Inconsistent & 82 & 33.1 & 52 & 28.7 & 40 & 44.8 & \\
\hline Condom use in the last sexual encounter $(n=992)$ & & & & & & & $<0.001$ \\
\hline No & 635 & 64.0 & 254 & 54.2 & 381 & 72.8 & \\
\hline Yes & 357 & 36.0 & 215 & 45.8 & 142 & 27.2 & \\
\hline Ever testing for HIV $(n=1185)$ & & & & & & & $<0.001$ \\
\hline Yes & 740 & 62.4 & 316 & 55.8 & 424 & 68.5 & \\
\hline No & 445 & 37.6 & 250 & 44.2 & 195 & 31.5 & \\
\hline Reported HIV status $(n=735)^{1}$ & & & & & & & 0.407 \\
\hline Negative & 720 & 97.3 & 307 & 97.5 & 413 & 98.3 & \\
\hline Positive & 15 & 2.0 & 8 & 2.5 & 7 & 1.7 & \\
\hline Ever utilization of health services in Portugal $(n=1186)$ & & & & & & & $<0.001$ \\
\hline No & 207 & 17.5 & 125 & 22.0 & 82 & 13.2 & \\
\hline Yes & 979 & 82.5 & 442 & 78.0 & 537 & 86.8 & \\
\hline $\begin{array}{l}\text { Attendance to a sexual and reproductive } \\
\text { consultation }(n=1169)\end{array}$ & & & & & & & $<0.001$ \\
\hline No & 876 & 74.9 & 489 & 87.6 & 387 & 63.3 & \\
\hline Yes & 293 & 25.1 & 69 & 12.4 & 224 & 36.7 & \\
\hline $\begin{array}{l}\text { Free condoms received in the previous } \\
12 \text { months }(n=1186)\end{array}$ & & & & & & & 0.047 \\
\hline Yes & 391 & 33.0 & 203 & 35.8 & 188 & 30.4 & \\
\hline No & 795 & 67.0 & 364 & 64.2 & 431 & 69.6 & \\
\hline
\end{tabular}


Of those ever tested for HIV, 15 participants (2.0\%) reported being HIV positive: $2.5 \%$ of men and $1.7 \%$ of women; $4.4 \%(n=12)$ of Africans, $1.2 \%(n=2)$ of Eastern Europeans and $0.3 \%(n=1)$ of Brazilians (data not shown in the table). HIV-positive participants reported high-risk sexual behaviors: nine participants $(60.0 \%)$ had two or more sexual partners in the last year, six $(40.0 \%)$ had occasional sexual partners and three $(20.0 \%)$ both regular and occasional sexual partners in the last year, four (26.7\%) inconsistently used condom with occasional partners and four (26.7\%) with regular partners. No significant differences were found across gender and origin.

Overall, 4.3\% $(n=50)$ of participants admitted having a STI in the previous year: $5.1 \%(n=31)$ of women and 3.5\% $(n=19)$ of men; $6.1 \%(n=24)$ of Africans, $4.0 \%(n=16)$ of Brazilians and $2.8 \%$ $(n=10)$ of Eastern Europeans.

\subsection{Use of Health Services and Preventive Initiatives}

Table 2 also shows the distribution of ever use of health services, attendance to a sexual and reproductive health consultation and free condoms received by gender. A significantly higher proportion of women reported having ever used the health services and having attended a sexual and reproductive health consultation, while men reported more frequently having received free condoms in the previous year. Participants who ever used health services reported more frequently having been tested for HIV compared to those who never used $(64.5 \%$ vs. $52.7 \%, p=0.001)$. Similar result was found for attending a sexual and reproductive health consultation $(74.7 \%$ among those who had attended $v$ s. $58.6 \%$ of those who never attended, $p<0.001$ ) (data not shown).

\subsection{Factors Associated with no Condom Use in the Last Sexual Intercourse}

Logistic regression estimation results for factors associated with the likelihood of not having used condom in the last sexual intercourse are presented in Table 3. After adjusting the logistic regression model to all variables presented in the analysis, having not used condom was more likely among women $(\mathrm{OR}=1.73,95 \% \mathrm{CI}: 1.25-2.40)$, Africans $(\mathrm{OR}=1.81,95 \% \mathrm{CI}: 1.11-2.96)$ compared to Eastern Europeans, those older ( $\mathrm{OR}=1.84,95 \% \mathrm{CI}: 1.02-3.32)$, those with elementary education $(\mathrm{OR}=1.84,95 \% \mathrm{CI}: 1.11-3.01)$ compared to higher education, those married $(\mathrm{OR}=2.38,95 \% \mathrm{CI}$ : 1.67-3.38) and those who didn't receive free condoms in the previous year (OR $=1.49,95 \%$ CI: 1.06-2.09). No condom use was less likely among immigrants who had only occasional sexual partners $(\mathrm{OR}=0.10,95 \% \mathrm{CI}: 0.05-0.20)$ and both regular and occasional sexual partners $(\mathrm{OR}=0.43$, 95\% CI: $0.25-0.75)$.

Table 3. Logistic regression results for factors associated with no condom use in the last sexual intercourse.

\begin{tabular}{lccc}
\hline & $\boldsymbol{n}(\mathbf{\%})(\boldsymbol{n}=\mathbf{6 3 5})$ & Crude OR $\mathbf{( 9 5 \%}$ CI) & Adjusted OR (95\% CI) ${ }^{\mathbf{1}}$ \\
\hline Sex & & & \\
$\quad$ Male & $254(54.2)$ & 1.00 & 1.00 \\
$\quad$ Female & $381(72.8)$ & $2.27(1.74-2.96)^{* * *}$ & $1.73(1.25-2.40)^{* *}$ \\
$\quad$ Origin & & & \\
$\quad$ Eastern European & $184(64.3)$ & 1.00 & 1.00 \\
\hline
\end{tabular}


Table 3. Cont.

\begin{tabular}{|c|c|c|c|}
\hline & $n(\%)(n=635)$ & Crude OR (95\% CI) & Adjusted OR (95\% CI) ${ }^{1}$ \\
\hline Brazilian & $215(57.5)$ & $0.75(0.55-1.03)$ & $1.05(0.68-1.61)$ \\
\hline African & $236(71.1)$ & $1.36(0.97-1.91)$ & $1.81(1.11-2.96)^{*}$ \\
\hline \multicolumn{4}{|l|}{ Age (years) } \\
\hline $18-24$ & $78(50.0)$ & 1.00 & 1.00 \\
\hline $25-44$ & $418(63.5)$ & $1.74(1.23-2.48)^{* *}$ & $1.20(0.77-1.87)$ \\
\hline $45-65$ & $139(78.1)$ & $3.56(2.22-5.73)^{* * *}$ & $1.84(1.02-3.32)^{*}$ \\
\hline \multicolumn{4}{|l|}{ Educational level } \\
\hline Higher & $206(61.9)$ & 1.00 & 1.00 \\
\hline Secondary & $235(59.0)$ & $0.89(0.66-1.20)$ & $1.40(0.95-2.07)$ \\
\hline Elementary & $191(74.3)$ & $1.78(1.25-2.55)^{* *}$ & $1.84(1.11-3.01)^{*}$ \\
\hline \multicolumn{4}{|l|}{ Marital status } \\
\hline Unmarried & $301(52.8)$ & 1.00 & 1.00 \\
\hline Married & $332(79.0)$ & $3.37(2.53-4.49)^{* * *}$ & $2.38(1.67-3.38)^{* * *}$ \\
\hline \multicolumn{4}{|l|}{ Number of sexual partners } \\
\hline 1 partner & 447 (75.4) & 1.00 & 1.00 \\
\hline 2-3 partners & $138(54.3)$ & $0.39(0.29-0.53)^{* * *}$ & $0.94(0.60-1.48)$ \\
\hline$\geq 4$ partners & $31(27.7)$ & $0.13(0.08-0.20)^{* * *}$ & $0.76(0.38-1.50)$ \\
\hline \multicolumn{4}{|c|}{$\begin{array}{l}\text { Type of sexual partners in the } \\
\text { previous } 12 \text { months }\end{array}$} \\
\hline Only regular & $546(75.6)$ & 1.00 & 1.00 \\
\hline Only occasional & $14(14.1)$ & $0.05(0.03-0.10)^{* * *}$ & $0.10(0.05-0.20)^{* * *}$ \\
\hline Regular and occasional & $71(44.7)$ & $0.26(0.18-0.37)^{* * *}$ & $0.43(0.25-0.75)^{* *}$ \\
\hline \multicolumn{4}{|c|}{$\begin{array}{l}\text { Free condoms received in the } \\
\text { previous } 12 \text { months }\end{array}$} \\
\hline Yes & $184(51.8)$ & 1.00 & 1.00 \\
\hline No & $451(70.8)$ & $2.25(1.72-2.95)^{* * *}$ & $1.49(1.06-2.09)^{* *}$ \\
\hline \multicolumn{4}{|l|}{ Ever testing for HIV } \\
\hline Yes & $410(62.6)$ & 1.00 & 1.00 \\
\hline No & $225(66.8)$ & $1.20(0.91-1.58)$ & $1.13(0.80-1.59)$ \\
\hline
\end{tabular}

\section{Discussion}

In general, the results of this study indicate high rates of risky sexual behaviors among immigrants, including having multiple (concurrent) sexual partners and unprotected sexual intercourse, consistently with other research conducted in Europe [6,31] and in other regions [9,29,32,33]. These findings highlight the potential increasing risk for HIV infection of migrants who have unprotected sex with multiple sexual partners, but also if they acquire HIV/AIDS the increasing likelihood of transmitting HIV infection to their partners.

As would be expected, we found wide variability in sexual risk behaviors across gender. Women reported significantly less condom use than men. This can be strongly related to gender power inequalities and lack of negotiating capacity to request safer sex, which renders women particularly vulnerable to partners' risk behaviors [34,35]. On the other hand, although consistent condom use was more frequent among men, the reported higher rates of multiple sexual partners, engagement in 
commercial sex and with same-sex partners puts this subgroup at increased risk for HIV infection. A key element to be explored in future research is the variations in the pattern of risk practices through the different phases of the migration process and within each geographic context.

The overall reported HIV prevalence in this study was $2 \%$ and $4.4 \%$ in the African subgroup, much higher compared to that estimated for the general national population $(0.7 \%$ among individuals aged 15-49 years) [17]. The scant published research in the European context show relatively great levels of infection. In a cross-sectional survey conducted in London with a convenience sample of Central and Eastern European migrants, $1.1 \%$ of respondents reported being HIV positive [6]. A study carried out in HIV counselling and testing clinics in several Spanish cities included a sample of immigrants who voluntarily tested for HIV and the HIV prevalence obtained ranged from 1.7\% in Central and Eastern Europeans and in Latin Americans, 2.4\% in North Africans and 8.4\% in Sub-Saharan Africans [36]. In other cross-sectional community-based survey conducted with 1006 black-Africans in England, $14 \%$ of participants tested HIV positive [30]. Given that our data is solely based on self-reported information with absence of biological samples, we can speculate that the proportion of HIV-positive immigrants among our sample is probably higher.

The greater prevalence of HIV among African immigrants found in our sample has also been described in other European studies [30,36-38]. This certainly can be related to the higher prevalence of HIV in their countries of origin but also to their greater exposure to HIV risk. Indeed, African immigrants reported higher rates of risk sexual behaviors (multiple sexual partners, concomitant partners in the last year and inconsistent condom use-from further analysis not shown). In future research it is essential to further explore the patterns of risk behaviors of migrants and the underlying individual, sociocultural and contextual factors as also the epidemiological background.

A relevant result in our study is the observation of risky sexual behaviors among HIV-positive immigrants. Although caution is needed when analyzing the results because the sample size is small, a relatively large proportion of these participants reported having multiple sexual partners, having both regular and occasional partners in the previous year and engaging in unprotected sex, which poses direct risks for HIV transmission. Secondary prevention strategies are warranted to foster safer sex practices among those living with HIV.

It is also important to point out the high reported prevalence of STI found in this study. There is clear evidence that STI increase the likelihood of HIV transmission and similar sexual behaviors place people at high risk of both infections [39]. Our findings reinforce the need of strengthening integrated HIV and STI prevention and control programs among immigrants.

Approximately $38 \%$ of immigrants in this study reported having never been tested for HIV and of those who ever tested, $63.4 \%$ were not tested in the last year. These may include a potential group of immigrants with undiagnosed HIV infection. Moreover, immigrants who never tested for HIV reported more frequently risky sexual behavior. Evidence gained in continued experience in HIV testing indicates that increasing individuals' awareness of HIV infection and counseling them to develop appropriate sexual protective measures leads to substantial reductions in high-risk sexual behavior [40-42]. Therefore, promotion of HIV testing among this population should be sustained.

When promoting HIV testing it must be taken into account the important finding observed in this study and in other research that having never been tested for HIV is significantly associated with having never used health services or attended a sexual reproductive health consultation $[43,44]$. 
Our results show a considerable proportion of immigrants who never used the health services, in line with previous studies [45-48]. Although no specific data were collected on barriers in utilization of health services, the literature points out migrants' lack of knowledge on the health services available, the lack of cultural competence of health professionals and structural barriers as cost, distance of health services and legal restrictions [12,46,49,50]. These findings support the need to overcome barriers and promote the use of health services in order to reduce missed opportunities for early detection of HIV and prevention among this population.

Immigrants who received free condoms were less likely to had unprotected sex, suggesting that the provision of free condoms to other immigrants can have the same benefits. Additionally, we found a relationship between low educational level and having not used condom in the last sexual intercourse. A possible explanation is that lower educational level, frequently related to the lack of knowledge on HIV transmission and prevention, may hinder risk perception and increase the adoption of unsafe sexual practices $[8,25,51,52]$. Community-based initiatives promoted by outreach teams who have trusting relationships with the community and have unique knowledge of its context can contribute to promote effective HIV prevention interventions among these populations [10,53].

The findings must be interpreted with consideration of some limitations. The cross-sectional nature of the data limits our ability to draw causal inferences. Another limitation relates to the sampling procedure. Although the study achieved a diverse and large sample we did not use a random sampling method to select the study population. In fact, the information available on immigrant population in Portugal does not allow constructing sampling frames for representative population-based surveys that capture hard-to-reach subgroups as undocumented and recent immigrants. Collecting data only from migrants presenting themselves at the NISC potentially leads to an overrepresentation of more affluent and better integrated migrant groups. However, as this center is viewed by immigrants as an independent institution dedicated to solving individual integration problems, we are confident that the sampling procedure allowed for a fairly representative sample of migrant conditions. Also, the participants' socio-demographic profiles are in line with data on immigrant populations in Portugal [19]. We did not collect data on reasons for refusals, but the topic explored in this study may have motivated individuals to refuse, which could mask a higher prevalence of risk behaviors and infection among this population. As in many other investigations, another limitation is the collected information based on self-reports. Due to the intimate and sensitive nature of the study subject and the high degree of stigma and discrimination attached to risky sexual behavior and HIV/STI positive serostatus, response bias toward under-reporting in this study would be expected.

Despite study limitations, this large-scale study provides useful insights on risky sexual behavior and HIV infection/STI among immigrants. In order to improve our understanding of the complex dynamics of HIV risk and infection in this population further research is needed.

\section{Conclusions}

In summary, this study shows that a considerable proportion of immigrants engage in risky sexual behaviors rendering them at high risk for HIV infection. Our findings highlight that efforts to promote HIV testing and awareness of HIV serostatus among immigrants as well as culturally adapted interventions promoting risk reduction strategies should be strengthened. Given the enormous 
heterogeneity of immigrant communities, tailored interventions should be developed targeting subgroups prone to high risk sexual behaviors and matching their specific prevention needs.

\section{Acknowledgments}

This work was partially supported by National Coordination for HIV/AIDS Infection. We wish to thank all participants of this study. We are very grateful to all the community partners of the project. We also would like to acknowledge the commitment of the team of interviewers who were responsible for the collection of the study data.

\section{Author Contributions}

Sónia Dias and Ana Gama designed the study and coordinated the data collection process. Adilson Marques and Maria O. Martins were responsible for all statistical analyses. All authors wrote, reviewed the manuscript and approved the final version.

\section{Conflicts of Interest}

The authors declare no conflict of interest.

\section{References}

1. ECDC. Assessing the Burden of Key Infectious Diseases Affecting Migrant Populations in the EU/EEA-Executive Summary; ECDC: Stockholm, Sweden, 2014.

2. Likatavicius, G.; van de Laar, M. HIV and AIDS in the European Union, 2011. Euro Surveill. 2012, 17. Available online: http://www.eurosurveillance.org/ViewArticle.aspx?ArticleId=20329 (accessed on 12 December 2012).

3. ECDC. Migrant Health: Epidemiology of HIV and AIDS in Migrant Communities and Ethnic Minorities in EU/EEA Countries; ECDC: Stockholm, Sweden, 2010.

4. Dosekun, O.; Fox, J. An overview of the relative risks of different sexual behaviours on HIV transmission. Curr. Opin. HIV AIDS 2010, 5, 291-297.

5. Gilbart, V.L.; Mercer, C.H.; Dougan, S.; Copas, A.J.; Fenton, K.A.; Johnson, A.M.; Evans, B.G. Factors associated with heterosexual transmission of HIV to individuals without a major risk within England, Wales, and Northern Ireland: A comparison with national probability surveys. Sex. Transm. Infect. 2006, 82, 15-20.

6. Burns, F.M.; Evans, A.R.; Mercer, C.H.; Parutis, V.; Gerry, C.J.; Mole, R.C.M.; French, R.S.; Imrie, J.; Hart, G.J. Sexual and HIV risk behaviour in central and eastern European migrants in London. Sex. Transm. Infect. 2011, 87, 318-324.

7. Sanchez, M.A.; Hernández, M.T.; Hanson, J.E.; Vera, A.; Magis-Rodríguez, C.; Ruiz, J.D.; Garza, A.H.; Castañeda, X.; Aoki, B.K.; Lemp, G.F. The effect of migration on HIV high-risk behaviors among Mexican migrants. J. Acquir. Immune Defic. Syndr. 2012, 61, 610-617.

8. Wang, K.-W.; Wu, J.-Q.; Zhao, H.-X.; Li, Y.-Y.; Zhao, R.; Zhou, Y.; Ji, H.L. Unmarried male migrants and sexual risk behavior: A cross-sectional study in Shanghai, China. BMC Public Health 2013, 13, doi:10.1186/1471-2458-13-1152. 
9. Wu, J.-Q.; Wang, K.-W.; Zhao, R.; Li, Y.-Y.; Zhou, Y.; Li, Y.-R.; Ji, H.L.; Ji, M. Male rural-to-urban migrants and risky sexual behavior: A cross-sectional study in Shanghai, China. Int. J. Environ. Res. Public Health 2014, 11, 2846-2864.

10. Hernandez, M.T.; Lemp, G.F.; Castañeda, X.; Sanchez, M.A.; Aoki, B.K.; Tapia-Conyer, R.; Drake, M.V. HIV/AIDS among Mexican migrants and recent immigrants in California and Mexico. J. Acquir. Immune Defic. Syndr. 2004, 37, s203-s217.

11. Dias, S.; Gama, A.; Rocha, C. Immigrant women's perceptions and experiences of health care services: Insights from a focus group study. J. Public Health 2010, 18, 489-496.

12. Scheppers, E.; van Dongen, E.; Dekker, J.; Geertzen, J.; Dekker, J. Potential barriers to the use of health services among ethnic minorities: A review. Fam. Pract. 2006, 23, 325-348.

13. WHO; UNAIDS; UNICEF. Global HIV/AIDS Response: Epidemic Update and Health Sector Progress towards Universal Access; WHO: Geneva, Switzerland, 2011.

14. Del Amo, J.; Bröring, G.; Hamers, F.; Infuso, A.; Fenton, K. Monitoring HIV/AIDS in Europe's migrant communities and ethnic minorities. AIDS 2004, 18, 1867-1873.

15. Salama, P.; Dondero, T.J. HIV surveillance in complex emergencies. AIDS 2001, 15, S4-S12.

16. ECDC/WHO. HIV/AIDS Surveillance in Europe 2012; ECDC: Stockholm, Sweden, 2013.

17. UNAIDS. UNAIDS Report on the Global AIDS Epidemic 2012; UNAIDS: Geneva, Switzerland, 2012.

18. OECD. International Migration Outlook 2013-OECD READ Edition; OECD: Paris, France, 2013.

19. SEF. Relatório de Imigração, Fronteiras e Asilo-2013; SEF: Lisboa, Portugal, 2014.

20. INSA. Infeção VIH/SIDA: A Situação em Portugal a 31 de Dezembro de 2012; INSA: Lisboa, Portugal, 2013.

21. SEF. Relatório de Imigração, Fronteiras e Asilo-2011; SEF: Lisboa, Portugal, 2012.

22. ACIDI. Handbook on How to Implement a One-Stop-Shop; ACIDI: Lisbon, Portugal, 2009.

23. Niessen, J.; Schibel, Y. Handbook on Integration for Policy-makers and Practitioners; European Commission: Brussels, Luxembourg, 2004.

24. IOM. International Migration Law: Glossary on Migration; IOM: Geneva, Switzerland, 2004.

25. Wang, Y.; Cochran, C.; Xu, P.; Shen, J.J.; Zeng, G.; Xu, Y.; Sun, M.; Li, C.; Li, X.; Chang, F.; et al. Acquired immunodeficiency syndrome/human immunodeficiency virus knowledge, attitudes, and practices, and use of healthcare services among rural migrants: A cross-sectional study in China. BMC Public Health 2014, 14, 158.

26. ECDC. Mapping of HIV/STI Behavioural Surveillance in Europe; ECDC: Stockholm, Sweden, 2009.

27. UNAIDS. Monitoring the Declaration of Commitment on HIV/AIDS-Guidelines on Construction of Core Indicators 2010 Reporting; UNAIDS: Geneva, Switzerland, 2009.

28. Evans, A.R.; Parutis, V.; Hart, G.; Mercer, C.H.; Gerry, C.; Mole, R.; French, R.S.; Imrie, J.; Burns, F. The sexual attitudes and lifestyles of London's Eastern Europeans (SALLEE Project): Design and methods. BMC Public Health 2009, 9, doi:10.1186/1471-2458-9-399.

29. Lurie, M.N.; Williams, B.G.; Zuma, K.; Mkaya-Mwamburi, D.; Garnett, G.; Sturm, A.W.; Sweat, M.D.; Gittelsohn, J.; Addool Karim, S.S. The impact of migration on HIV-1 transmission in South Africa: A study of migrant and nonmigrant men and their partners. Sex. Transm. Dis. 2003, 30, 149-156. 
30. Sadler, K.E.; McGarrigle, C.A.; Elam, G.; Ssanyu-Sseruma, W.; Davidson, O.; Nichols, T.; Mercey, D.; Parry, J.V.; Fenton, K.A. Sexual behaviour and HIV infection in black-Africans in England: Results from the Mayisha II survey of sexual attitudes and lifestyles. Sex. Transm. Infect. 2007, 83, 523-529.

31. Gras, M.; van Benthem, B. Determinants of high-risk sexual behavior among immigrant groups in Amsterdam: Implications for interventions. J. Acquir. Immune Defic. Syndr. 2001, 28, 166-172.

32. Saggurti, N.; Verma, R.K.; Jain, A.; RamaRao, S.; Kumar, K.A.; Subbiah, A.; Modugu, H.R.; Halli, S.; Bharat, S. HIV risk behaviours among contracted and non-contracted male migrant workers in India: Potential role of labour contractors and contractual systems in HIV prevention. AIDS 2008, 22, S127-S136.

33. Tuan, N.A.; Fylkesnes, K.; Thang, B.D.; Hien, N.T.; Long, N.T.; Kinh, N.V.; Thang, P.H.; Manh, P.D.; O'Farrell, N. Human immunodeficiency virus (HIV) infection patterns and risk behaviours in different population groups and provinces in Viet Nam. Bull. World Health Organ. 2007, 85, 35-41.

34. Llácer, A.; Zunzunegui, M.V.; del Amo, J.; Mazarrasa, L.; Bolumar, F. The contribution of a gender perspective to the understanding of migrants' health. J. Epidemiol. Commun. Health 2007, 61, ii4-ii10.

35. Shedlin, M.G.; Drucker, E.; Decena, C.U.; Hoffman, S.; Bhattacharya, G.; Beckford, S.; Barreras, R. Immigration and HIV/AIDS in the New York Metropolitan Area. J. Urban Health 2006, $83,43-58$.

36. Castilla, J.; Sobrino, P.; del Amo, J. HIV infection among people of foreign origin voluntarily tested in Spain. A comparison with national subjects. Sex. Transm. Infect. 2002, 78, 250-254.

37. Gras, M.J.; Weide, J.F.; Langendam, M.W.; Coutinho, R.A.; van den Hoek, A. HIV prevalence, sexual risk behaviour and sexual mixing patterns among migrants in Amsterdam, The Netherlands. AIDS 1999, 13, 1953-1962.

38. Xiridou, M.; van Veen, M.; Coutinho, R.; Prins, M. Can migrants from high-endemic countries cause new HIV outbreaks among heterosexuals in low-endemic countries? AIDS 2010, 24, 2081-2088.

39. Wasserheit, J. Epidemiological synergy: Interrelationships between human immunodeficiency virus infection and other sexually transmitted diseases. Sex. Transm. Dis. 1992, 19, 61-77.

40. Agha, S. Factors associated with HIV testing and condom use in Mozambique: Implications for programs. Reprod. Health 2012, 9, doi:10.1186/1742-4755-9-20.

41. Fenton, K.A. Sustaining HIV prevention: HIV testing in health care settings. Top. HIV Med. 2007, $15,146-149$.

42. Gilbert, P.A.; Rhodes, S.D. HIV testing among immigrant sexual and gender minority Latinos in a US region with little historical Latino presence. AIDS Patient Care STDs 2013, 27, 628-636.

43. Donker, G.; Dorsman, S.; Spreeuwenberg, P.; van den Broek, I.; van Bergen, J. Twenty-two years of HIV-related consultations in Dutch general practice: A dynamic cohort study. BMJ Open 2013, 3, doi:10.1136/bmjopen-2012-001834.

44. Petroll, A.E.; DiFranceisco, W.; McAuliffe, T.L.; Seal, D.W.; Kelly, J.A.; Pinkerton, S.D. HIV testing rates, testing locations, and healthcare utilization among urban African-American men. J. Urban Health 2009, 86, 119-131. 
45. De Luca, G.; Ponzo, M.; Andrés, A.R. Health care utilization by immigrants in Italy. Int. J. Health Care Financ. Economics 2013, 13, 1-31.

46. Dias, S.F.; Severo, M.; Barros, H. Determinants of health care utilization by immigrants in Portugal. BMC Health Serv. Res. 2008, 8, doi:10.1186/1472-6963-8-207.

47. Dias, S.; Gama, A.; Cortes, M.; de Sousa, B. Healthcare-seeking patterns among immigrants in Portugal. Health Social Care Commun. 2011, 19, 514-521.

48. Fenta, H.; Hyman, I.; Noh, S. Health service utilization by Ethiopian immigrants and refugees in Toronto. J. Immigr. Minor. Health 2007, 9, 349-357.

49. Dias, S.; Gama, A.; Cargaleiro, H.; Martins, M.O. Health workers' attitudes toward immigrant patients: A cross-sectional survey in primary health care services. Hum. Resour. Health 2012, 10, doi:10.1186/1478-4491-10-14.

50. Priebe, S.; Sandhu, S.; Dias, S.; Gaddini, A.; Greacen, T.; Ioannidis, E.; Kluge, U.; Krasnik, A.; Lamkaddem, M.; Lorant, V.; et al. Good practice in health care for migrants: Views and experiences of care professionals in 16 European countries. BMC Public Health 2011, 11, doi:10.1186/1471-2458-11-187.

51. Lammers, J.; van Wijnbergen, S.J.; Willebrands, D. Condom use, risk perception, and HIV knowledge: A comparison across sexes in Nigeria. HIV/AIDS 2013, 5, 283-293.

52. Zafar, M.; Nisar, N.; Kadir, M.; Fatmi, Z.; Ahmed, Z.; Shafique, K. Knowledge, attitude and practices regarding HIV/AIDS among adult fishermen in coastal areas of Karachi. BMC Public Health 2014, 14, doi:10.1186/1471-2458-14-437.

53. McCoy, H.V.; Hlaing, W.M.; Ergon-Rowe, E.; Samuels, D.; Malow, R. Lessons from the fields: A migrant HIV prevention project. Public Health Rep. 2009, 124, 790-796.

(C) 2014 by the authors; licensee MDPI, Basel, Switzerland. This article is an open access article distributed under the terms and conditions of the Creative Commons Attribution license (http://creativecommons.org/licenses/by/3.0/). 